\title{
Irish psychiatric absconders: characteristics and outcome
}

\author{
E. Walsh, S. Rooney, D. Sloan, P. McCauley, F. Mulvaney, E. O'Callaghan \\ and C. Larkin
}

\begin{abstract}
Absconding constifutes a significant clinical problem, loading to high levels of anxiety among staff. Ninetyfive poychiatric in-patients who cbsconded from an Irish hospltal over a period of 12 months were reviewed retrospectively. Absconders were significantly more likely to be single and compulsorily detained with a diagnosis of schizophrenia or personality disorder when compared to the remaining hospltal population for that year. Common destinations included the public house and home, with most returning of their own voltion within 24 hours. The rates of self-harm and violence against others are recorded.
\end{abstract}

When a patient goes missing from a psychiatric hospital much time and effort is expended in the subsequent search. Not only may the patient be at risk but so may members of the public. It is important from a management point of view to identify subgroups of patients most likely to abscond. Following studies published in the 1960s (Muller, 1962, Antebi, 1967), in the aftermath of the new open door policy resulting from the 1959 Mental Health Act, there was until recently a paucity of research on patients who abscond from psychiatric hospitals. Despite differences in definitions and methodology, findings from more recent studies (Tomison, 1989; Falkowski et al, 1990; Farragher et al, 1996) largely concur with earlier work that was carried out. Absconders have been found to be significantly more likely to be compulsorily admitted if they are male (Tomison, 1989) or from ethnic minorities (Falkowski et al, 1990). Farragher et al (1996) in the only Irish study published to date, found absconders significantly more likely to be compulsorily detained and showed a trend for them to be single males with a diagnosis of schizophrenia, personality disorder or alcohol dependence.

The aims of this study were to define the socio-demographic and clinical characteristics of a group of patients who absconded from an Irish psychiatric hospital, to assess whether the profile of absconders is similar to British absconders, to identify commonly chosen destinations, to record the rate of destructive behaviour to self or others, and to examine the outcome of these incidents.

\section{The study}

St John of God Hospital provides in-patient psychiatric treatment and accepts referrals from all parts of Ireland. In addition, it serves a population of approximately 180000 in the local catchment area of south-east County Dublin. The areas of the hospital studied included all hospital wards (two acute locked wards, two open rehabilitation wards, a psychogeriatric unit and an adolescent unit), two day hospitals and the occupational therapy department.

For the purposes of this study an 'absconder' was defined as a patient who was absent from the hospital building and grounds without permission from staff. Those who were missing, but subsequently found within the hospital grounds were excluded, as were those who failed to return from leave, and those discharged against medical advice.

Absconders were identified by reviewing the 24-hourly nursing reports for one calendar year. Data collection for each episode of absconding based on medical and nursing case notes included socio-demographic details, admission status, discharge diagnosis, time of leaving. destination, mode of return and outcome. Diagnosis was recorded using ICD-9 classification (World Health Organization, 1978). Data drawn from the hospital's computerised patient information system were used to compare the study group with the hospital population $(n=1237)$ for that year. The data were analysed using the Statistical Package for the Social Sciences (SPSS/PC+).

\section{Findings}

\section{Socio-demographic characteristics}

A total of 1771 admissions involving 1332 patients were recorded during the time period and 95 patients absconded a total of 156 times. Of the total 156 absconding incidents, females 
accounted for $55 \%(n=85)$ and males $45 \%(n=71)$. Forty-nine men absconded a total of 71 times. Twelve men absconded more than once. Fortysix women absconded a total of 85 times. Fourteen women absconded more than once. The average age of the absconders was 32 years for men and 32 years for females versus 35 years for men and 33 years for females in the control group. Seventy per cent of absconders were single compared with $34 \%$ of controls $(P<0.001)$. In addition, absconders were significantly more likely to be compulsory patients $(24 \%)$ when compared with controls $(4 \%)$ $(P<0.001)$.

\section{Psychiatric diagnosis}

The most common discharge diagnoses for the absconding group were schizophrenia (40\%) and personality disorder (19\%). These diagnoses were less prevalent among controls, 20 and $3 \%$ respectively. Diagnoses of schizophrenia and personality disorder were over-represented in the absconding group $\left(\chi^{2}=98.73\right.$, d.f. $=5$, $P<0.001)$ with diagnoses of affective disorder, depressive neurosis and alcohol dependence under-represented compared to controls.

\section{Time and place of absconding}

The most frequent time of day for absconding was between the hours of 13.30 and 21.00 , with $70 \%(n=109)$ of patients leaving during this time. Absconding was most likely to occur in the earlier part of the week, with the weekend having the lowest rate. The most common months for absconding were May, June, August and September, showing a definite summer peak that was statistically significant compared to the total number of admissions for each month $\left(\chi^{2}=36.4\right.$, d.f. $=11, P<0.001)$. The majority of patients left from the two open rehabilitation wards.

\section{Outcome of absconding incident}

Patients returned in $91 \%(n=142)$ of incidents. In $62 \%(n=97)$ of cases patients returned of their own volition, were accompanied by family or friends in $19 \%(n=30)$, or by the police in $6 \%$ $(n=9)$ and by hospital staff in $5 \%(n=8)$. Of those who did return $80 \%$ came back within 24 hours.

The most common destinations were the public house $(28 \%, n=44)$, own home $(20 \%, n=31)$ and friend's home $(13 \%, n=20)$. It was not possible to establish the patient's destination in $41 \%(n=64)$ of cases.

There were no fatalities among the absconding group during the study year. Nine patients inflicted harm to themselves while absent from hospital: self-mutilation, self-poisoning, injury in a self-inflicted road traffic accident and hypothermia secondary to exposure. Two ab- sconders physically assaulted others and five absconders damaged property outside the hospital.

On return four patients $(2 \%)$ were transferred to a general medical hospital for treatment, medication was changed in $16 \%(n=25)$ of cases, patients were transferred to a secure ward in $15 \%(n=23)$ and in $7 \%(n=11)$ status was changed from informal to formal.

\section{Comment}

Absconders when compared to the remaining hospital population were significantly more likely to be single, formally admitted patients with a diagnosis of schizophrenia or personality disorder. These findings are in agreement with the previous Irish study and show that the characteristics of Irish absconders conform largely with those in mainland Britain. We confirmed the most consistent finding that compulsorily detained patients have the highest absconding rate (Tomison, 1989; Falkowski et al, 1990; Farragher et al, 1996) but failed to find a gender effect. This study replicates Muller's (1962) finding of a seasonal variation in absconding. Most absconders left at the time of maximum staffing levels showing that high staffing levels fail to deter absconders. It is noteworthy that in other studies, most abscondences were from disturbed or locked wards but in this study most absconding took place from the rehabilitation wards.

Previous studies have found that 65 to $90 \%$ of patients returned. The $91 \%$ returning in this study is the highest documented.

When initiating a search for a missing patient. apart from carefully documenting all information, informing relevant staff, checking the hospital and immediate environs and contacting relatives, we found that the public house may be a good place to start looking. A telephone call to the patient's own home or to that of a close friend is also useful. Nine absconders harmed themselves, two members of the public were hurt and property was also damaged. Apart from the more obvious harm that patients may inflict on themselves while absent, absconding may lead to a host of more subtle complications. for example the breakdown of trust with hospital staff, distress to relatives and disruption of the treatment process. Falkowski et al (1990) retrospectively described suicide in six patients within 18 months of absconding and this led to the suggestion that absconding during treatment may be a risk factor for subsequent suicide. This question deserves more attention. 


\section{References}

ANTEBI, R. (1967) Some characteristics of mental hospital absconders. British Journal of Psychiatry. 113, 10871090.

FALKOWSK, J., WATTS, J., FalkowsK, W., et al (1990) Patients leaving hospital without the knowledge or permission of staff-absconding. British Journal of Psychiatry, 166, 488-490.

FARRAGHER, B., GANNON, M. \& AHMAD, I. (1996) Absent without leave - can we predict those who go AWOL? The Irish Journal of Psychological Medicine, 13, 28-30.

MULLER, D. S. (1962) The missing patient. British Medical Journal, i, 177-179.

TOMison, A. R. (1989) Characteristics of psychiatric hospital absconders. British Journal of Psychiatry. 154, 368-371.

WORLD HEALTH ORganization (1978) Mental Disorders: Glossary and Guide to their Classification in
Accordance with the Ninth Revision of the Internationa Classification of Diseases (ICD-9). Geneva: WHO.

*Elizabeth Walsh, Clinical Research Fellow, Department of Psychological Medicine, 103

Denmark Hill, London SE5 8AF, Siobhán Rooney. Registrar, Trinity Court, Dublin, Darina Sloan, Senior Registrar, Uniwersity College, Galway, Patricia McAuley, Consultant Psychiatrist, Queen's Medical Centre, Nottingham. Flona Mulvaney, Research Assistant, St John of God Hospital Dublin. Eadbhard O'Callaghan, Consultant Psychiatrist, Cluain Mhuire Child and Family Centre, Dublin, and Conal Larkin, Medical Director, St John of God Hospital, Dublin

*Correspondence

\title{
FORTHCOMING FROM GASKELL
}

\section{Ethnicity: An Agenda for Mental Health}

\author{
Edited by Dinesh Bhugra
}

This book sets the scene for identifying and meeting the mental health needs of black and minority ethnic groups. Clinicians, researchers, academics, hospital managers, commissioners and voluntary organisation workers come together to discuss the problems in health care delivery and the way of moving the agenda forward. In addition to multi-disciplinary working the key emphasis here is in involving commissioners and voluntary organisations in deciding how best to meet the needs of the communities.

Features:

- setting the agenda for meeting the needs of minority ethnic groups

- multi-disciplinary input

- multi-speciality within psychiatry

Readership: $\quad$ Mental health professionals, eg. psychiatrists, trainees, nurses, occupational therapists, psychologists and social workers, healthcare managers

Autumn 1998, £15.00 approx, 200pp approx, Paperback, ISBN 1901242153

14. Royal College of Psychiatrists, 17 Belgrave Square, London SW1X 8PG

EJ Tel: 0171-235 2351, ext 146 Fax: 0171-245 1231 http://www.repsych.ac.uk 